\title{
"Quem tem o poder, tem o direito". Marx e a relação entre o Direito e a Revolução a partir do jornal Nova Gazeta Renana de 1848-1849
}

Ana Letícia Medeiros Godoi Silva*

Resumo: O artigo que ora apresentamos é a iniciativa de trazer à tona uma obra de Marx um tanto esquecida pela tradição. A Nova Gazeta Renana é um jornal rico em análises sobre a Primavera dos Povos (1848-1849) e que traz reflexões profundas sobre o universo político. Para tal, nos voltamos para a relação entre o campo jurídico e a revolução, tão explorada ao longo dos artigos do jornal. Uma vez que este âmbito é o caminho utilizado pela revolução alemã naqueles anos e sua compreensão nos permite entender os meandros que constituem a contrarrevolução instaurada à época, favorecendo sua consolidação e consumação. Esse tema é fundamental para a compreensão da própria noção de revolução em Marx, pois a tensão entre esta e a contrarrevolução é um tema para o autor ao longo daqueles anos. Assim, a necessidade do resgate de tal tema, na contemporaneidade, se faz presente e buscamos contribuir nessa direção.

Palavras-chave: Marx, direito, revolução, contrarrevolução

Abstract: The present article is an attempt to bring out a Karl Marx work that has been forgotten by tradition. The Neue Rheinische Zeitung is a rich newspaper, full of analysis of the revolution of 1848 and 1849, that brings deep reflexions towards the political universe. Therefore we intend to establish the relationship between law and revolution, which is an accurately examined theme by the paper's articles. Since the legal field was the path taken by the german revolution that time, if one understands this revolution, one can also detect the way that led to the

* Mestranda do Programa de Pós - Graduação de Filosofia da Universidade Federal de Minas Gerais. E-mail: almgodoi@gmail.com. 
counter-revolution and its consolidation. This theme is fundamental to understand Marx's concept of revolution itself, because the tension between this and the counter-revolution was a question to this author along those years. Therefore, there is a need to rescue these topics on the contemporary era and we long to make a contribution on this direction.

Keywords: Marx, right, revolution, counter-revolution

O presente artigo busca tratar a relação entre o âmbito jurídico e a revolução, especificamente durante os processos revolucionários de 1848-1849, a partir das análises encetadas por Marx em seu jornal a Nova Gazeta Renana, diário publicado visando a intervenção nos eventos cotidianos daquele período. Tais análises, por suas características, nos possibilitam a reconstrução do pensamento do filósofo alemão acerca de questões como revolução, partido, classes sociais, Estado e a relação entre o campo político-jurídico e a revolução, este último de nosso interesse imediato. Em grandes processos revolucionários, percebemos que as leis são utilizadas, em diversos momentos, para determinar os rumos dos acontecimentos e esse caminho favorece a contrarrevolução, como a história nos demonstra.

Nos processos revolucionários de 1848, no qual assistimos o primeiro levante da classe trabalhadora, Marx analisa profundamente este fenômeno que à época é determinante no caso alemão, no qual o campo jurídico é utilizado para deslegitimar a revolução, fortalecer a contrarrevolução e minar as convulsões sociais. Em seu jornal (que trataremos a partir de agora por NGR), o filósofo alemão reflete sobre os empreendimentos legislativos da burguesia e seus impactos para a revolução alemã. Ora, a análise profunda sobre a relação entre o universo jurídico e os processos revolucionários é fundamental na contemporaneidade e, por isto, retomar o pensamento de Karl Marx nos propicia alicerces sólidos na investigação. E, neste sentido, retomar a NGRéuma tarefa posta a qualquer estudioso do pensamentomarxiano,

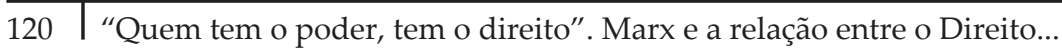


visto se tratar de um repositório categorial de rara importância em seu itinerário e que carrega tal temática profundamente desenvolvida.

$\mathrm{O}$ esquecimento deste periódico em nossos dias é resultado do trágico infortúnio que se abateu sobre o marxismo no século $X X$, mas que nem sempre se apresentou desta forma. No início do século passado, teóricos e revolucionários tomaram a NGR como referência, tanto para a intervenção cotidiana, quanto como ponto de partida para sua elaboração. Exemplo disso, são as elaborações de Lenin, sobre a ditadura democrática do proletariado e do campesinato ${ }^{1}$, e a teoria da revolução permanente de Trotsky². Ambas partiram da NGR e tomaram seu conteúdo como parte de seu desenvolvimento. Além disso, noções presentes na obra de Marx, e frequentemente desenvolvidas na gazeta, propiciaram o desenvolvimento de conceitos consagrados na tradição marxista que se seguiu, como Via Prussiana também de Lenin e Revolução Passiva de Antonio Gramsci. Ambas, inclusive, relacionadas com o tema central do presente artigo.

No entanto, o que pretendemos no momento não é empreender uma análise da recepção do jornal no curso do século XX, é resgatar tal obra de seu esquecimento através da leitura imanente dos textos que enfocam a questão em tela, e justamente por esta opção metodológica, nos restringimos a apresentar os artigos do jornal.

Para tal, é necessário compreender o contexto da Alemanha (estado ainda não unificado) em 1848. A burguesia alemã é lançada

${ }^{1}$ Com relação ao tema ver: LENINE, V. I. Duas táticas da social-democracia na revolução democrática. In: Obras Escolhidas. São Paulo: Editora Alva-Omega, 1979, no qual elabora sua tese acerca do processo revolucionário a partir da NGR.

${ }^{2}$ A este respeito verificar TROTSKY, León. Resultados y perspectivas. In: La teoría de la revolución permanente (compilación). Buenos Aires, Ediciones CEIP “, 2005. p.65125. Apesar de menos explícita a influência da NGR do que em Lenin, é inegável a qualquer leitor atento que tanto o balanço de 1848, apresentado por Trotsky, quanto sua elaboração sobre a revolução possuem forte ligação com o jornal. Além disso, em TROTSKY, León. Minha Vida: Ensaio Autobiográfico. Trad. Lívio Xavier. 2a Ed. Rio de Janeiro: Paz e Terra, 1978. Trotsky menciona que à época de seus primeiros escritos sobre a revolução permanente, tomava a NGR como modelo. 
ao poder através dos processos revolucionários iniciados em março daquele ano e se mostra pouco propensa a levar adiante seus próprios interesses, preferindo unir-se à aristocracia feudal na tentativa de barrar os processos em curso devido às suas próprias características como classe social. Sua debilidade, fraqueza de ação e covardia - já ressaltadas por Marx desde 1843 - elucidam sua postura diante da revolução.

Para garantir que as reivindicações das classes populares não acarretem transformações profundas nas relações existentes no interior da Alemanha, foi necessário barrar o processo revolucionário e para cumprir essa função surge a 'teoria ententista'. Se "inventou a teoria ententista para salvar o terreno do direito, ou seja, para defraudar, antes de tudo, a revolução do honneurs ${ }^{3}$ que lhe cabiam" (MARX, 2010, p. 318 $)^{4}$, pois ao permanecerem as bases jurídicas inalteradas, a transformação nas velhas formas de dominação não se efetivaria em sua plenitude. Assim, o que Marx chama de teoria ententista é a postura conciliatória que a burguesia apresenta frente à nobreza em uma tentativa de amortecer o processo revolucionário.

É inerente ao processo deflagrado em 18 de março $^{5}$ o questionamento às bases constitucionais, não apenas prussianas, mas dos demais estados alemães uma vez que estas bases legitimam a dominação sofrida pelas classes populares. Assim, tal questionamento gera uma reação para impedir que a legislação existente fosse substituída por outra que correspondesse a nova forma de organização social. E para tal, a burguesia cumpre um papel determinante pois, ao ser alçada ao topo do governo pelas convulsões sociais, trai a revolução aliando-se à nobreza e com isso impedindo a efetivação das reivindicações da classe trabalhadora. No lugar disso, ela "engendrou

3 Grifo de Marx.

${ }^{4}$ As citações a partir deste ponto são extraídas da Nova Gazeta Renana e, justamente por este motivo, não nos referenciamos à obra.

${ }^{5}$ Em 18 de março inicia-se o processo revolucionário prussiano. 
eleições indiretas, que redundaram numa Assembleia para a qual o governo pode trovejar", “(...) chamou de volta o príncipe da Prússia, o chefe da contrarrevolução", "(...) deixou em vigor a velha legislação prussiana sobre os crimes políticos e os antigos tribunais. Sob seu governo, a antiga burocracia e o antigo exército tiveram tempo para se recuperar do susto e se recompor completamente. Sem qualquer restrição, todos os chefes do antigo regime permaneceram em seus postos" (p. 319). E a esse movimento, esta relação estabelecida entre burguesia e nobreza, Marx denomina de "teoria ententista", por refletir a intenção de se entender com a coroa manifestada desde o início por aqueles que assumiram o governo.

E tal intenção, pronunciada desde o início do processo revolucionário, é o reflexo da inaptidão e debilidade da burguesia alemã. O caráter desta classe já se pronunciava antes mesmo de 1848 e se expressa de forma mais contundente quando os acontecimentos a levam à ponta do processo revolucionário sem, no entanto, se expressar enquanto classe universal, sem se colocar como alternativa à aristocracia feudal, como ocorreu nos casos precedentes àquele ano.

E estes homens que assumiram o poder, somente pelo processo revolucionário, “(...) não foram nada além do que os órgãos de uma classe. Sua linguagem, seus atos não foram nada além do que o eco oficial de uma classe que os havia empuxado ao primeiro plano. Não foram mais que a grande burguesia - no primeiro plano (...)" (p. 320), demonstrando que cada ação perpetrada por eles não era meramente fruto de uma vontade individual mas, sim, do interesse de um grupo social.

A conciliação, no caso alemão, é possível porque tanto os interesses da nobreza quanto os interesses da burguesia se convergiam naquele momento, pois a “(...) nobreza estava essencialmente aburguesada. Em lugar de fidelidade, amor e fé, traficava agora principalmente, com beterrabas de açúcar, aguardente e lã. Seu torneio principal tornava-se o mercado de lã"(p. 320). Tal aburguesamento é fruto das transformações pela qual passa a sociedade alemã, que 
naquele momento já apresenta em seu seio relações de tipo capitalista, com a existência de indústrias e o desenvolvimento de um mercado, das quais a nobreza é parte integrante. Porém, isso não significa dizer que a nobreza deixa de ser o que é para se tornar parte da burguesia existente. Ela apenas se desloca no interior das relações sociais para um terreno mais próximo ao da burguesia e, justamente por isso, uma conciliação entre as duas está aquém das necessidades desta última pois

(...) o estado absolutista, cuja a base social havia desaparecido sob seus pés, como por encanto, com o curso do desenvolvimento, tornara-se um entrave para a nova sociedade burguesa, com seu modo de produção modificado e suas necessidades alteradas. Era preciso que a burguesia reivindicasse sua parte no domínio político, desde logo pelos interesses materiais. (...) Para alcançar seu fim, tinha que poder debater livremente seus interesses, suas opiniões e os negócios do governo (p. 320-321).

Para a burguesia, são colocadas as tarefas necessárias para executar a fim de desenvolver plenamente suas atividades que lhe são características. Mas, para ela, assumir tal postura significava se colocar ao lado do povo contra a nobreza. Porém, a história já havia lhe demostrado que, o povo ao não mais se movimentar impulsionado pelo interesse burguês, pode tornar-se perigoso. Logo, tornava-se mais cômodo para ela aliar-se à nobreza contra o povo, sacrificando alguns de seus interesses. "Face a face com o governo, não poderia naturalmente reivindicar os direitos e as liberdades que aspirava para si, a não ser que se apresentasse sob a razão social dos direitos e liberdades do povo" (p.321). Nesse sentido, "a burguesia só tinha uma missão, instalar-se comodamente na sua dominação, eliminar os anarquistas perturbadores, restabelecer 'a calma e a ordem' e recuperar os lucros perdidos durante a tempestade de março" (p. 327). 
Para tal, é necessário negar a revolução, mesmo que esta represente a legitimação da ascensão da burguesia ao poder. Negar a revolução é negar as reivindicações populares, seu acesso ao poder constituído após março. A revolução é transformada em um simples "acontecimento" ${ }^{\prime}$ pelo ministério burguês, garantindo assim legalmente a remoção das conquistas de março da classe trabalhadora. "A revolução era o protesto do povo contra a entente da burguesia com a Coroa. A burguesia, entendendo-se com a Coroa, devia protestar, portanto, contra - a revolução" (p. 328).

O processo de negação da revolução e das conquistas das classes populares inicia-se imediatamente após os levantes de março. Ao longo de 1848, observam-se medidas tomadas para, cada vez mais, alijar do processo trabalhadores, camponeses e pequeno-burgueses. E tais medidas foram tomadas no campo jurídico, campo este que, devido seu caráter de mantenedor das relações existentes, se opõe ao campo revolucionário. A burguesia não liquida a antiga constituição feudal, ao contrário, ela transporta o conjunto de leis feudais para o interior da nova legislação no intuito de legitimá-la. E é justamente por meio deste artifício que é capaz de garantir a permanência dos privilégios da nobreza e retirar qualquer vitória do povo. Assim, o novo governo burguês se porta como o "leal herdeiro" da Dieta Unificada7 e executor da legislação conciliadora.

A primeira medida nesse sentindo é a promulgação da lei eleitoral. Uma das principais reivindicações das barricadas de março

\footnotetext{
${ }^{6}$ Referência ao artigo de $n^{\circ} 3$ intitulado "A declaração de Camphausen na sessão de 30 de maio", da NGR.

7 A Dieta Unificada reúne-se pela primeira vez entre 11 de abril de 1847 a 26 de junho de 1847, representa a união das oito Dietas Provinciais. Convocada a critério do rei, se divide em duas câmaras: a câmara do estamento senhorial composta por 70 representantes da alta nobreza e a câmara dos três estamentos restantes(237 representantes da cavalaria, 182 das cidades e 124 dos municípios rurais). As atribuições da Dieta Unificada limitam-se à autorização de novos empréstimos em tempos de paz e à votação de novos impostos ou aumento destes.
} 
são eleições diretas, posto que a grande maioria da população não possuem acesso ao voto, mas tal proposta compromete o poder da nobreza e da burguesia, cuja composição parlamentar se altera com a interferência do voto popular. Logo, é elaborada uma lei eleitoral com votação indireta, com aval da Dieta Unificada, órgão feudal que é questionado pelo movimento revolucionário e que, consequentemente, precisa ser abolido do sistema judiciário moderno.

Um acontecimento ilegal faz do sr. Camphausen um primeiroministro responsável, um ministro constitucional - uma pessoa ilegal no sentido da "velha" "constituição existente". O ministro constitucional faz, de modo ilegal, da inconstitucional, estamental fiel amada "Unificada" uma Assembleia constituinte. A fiel amada "Unificada" faz, de modo ilegal, a lei da eleição indireta. A lei da eleição indireta faz a Câmara de Berlim, e a Câmara de Berlim faz a constituição, e a constituição faz todas as câmaras seguintes para todo sempre" (p. 87).

Percebe-se assim que o "terreno do direito" é o terreno da ação burguesa, pois para efetivar suas intenções conciliatórias e, ao mesmo tempo, de dominação é necessário se afastar do campo revolucionário e, para tal, adota medidas ao longo do ano de 1848 que possuem caráter ilegítimo do ponto de vista da revolução, uma vez que legitimam um conjunto de leis questionadas pelo próprio processo de março. As noções de legitimação e legalidade são retiradas do campo revolucionário, ao qual pertencem primeiramente, e são transportadas artificialmente para o campo jurídico, tendo em vista que este movimento favorece as classes que estão no poder. "Nada mais fácil do que, sobre esta base, aniquilar a posteriori todas as conquistas da revolução no interesse do tesouro público! As evidentes reivindicações, necessidades e direitos da revolução naturalmente não são sancionadas por uma legislação cujos fundamentos foram pelos ares graças a essa revolução" (p. 107). 
Fica claro, portanto, que a partir do "terreno do direito" manifesta-se a ação estatal, pois cada lei promulgada está a serviço de uma política desenvolvida por aqueles que detêm o poder. A administraçãoburocráticaéem si mesmaimpotente paraimplementar qualquer medida adotada, mesmo que seja de seu interesse e através de seu braço jurídico, legitima ações de interesse de classe, no caso, da burguesia.

Assim, medidas no campo jurídico são implementadas para pôr fim à ameaça revolucionária e consolidar o poder constituído a partir da conciliação entre burguesia e nobreza. Uma destas medidas, que permite visualizar tal empresa burguesa, diz respeito aos encargos feudais, base de dominação da nobreza sobre o campesinato, dado que as leis promulgadas não alteram substancialmente as relações no campo, suprimem alguns dos encargos, mas, sua base de sustentação, a corveia, permanece intacta. Isso porque, suprimir as obrigações dos camponeses para com a nobreza significa a conversão daqueles em proprietários livres, abalando, assim, a estrutura de dominação feudal e, consequentemente, o meio de sustentação da nobreza enquanto classe. E, em um contexto de conciliação, não há possibilidade de implementação destas medidas.

O processo de março "tornava impossíveis para o futuro todas essas relações feudais. Os camponeses, como é natural, revogaram-nas imediatamente na prática. O governo nada mais tinha a fazer senão legalizar a supressão de todas as obrigações feudais já realizada na prática pela vontade do povo"(p. 121). Todavia, em sentido contrário, o governo toma medidas para restabelecer os laços feudais, obriga os camponeses a retornarem à sua condição de exploração e assim fica patente que tanto a revolução no campo quanto a revolução na cidade são negadas pela burguesia no poder.

A negação da revolução no campo é uma prova concludente da debilidade da burguesia prussiana, e de como a revolução alemã de 1848 está aquém, historicamente, dos processos que a antecederam. Tanto a burguesia como o campesinato têm como pressuposto para 
o pleno desenvolvimento de suas atividades a abolição dos encargos feudais e a produção assentada na propriedade privada e no livre tráfego de mercadorias, donde se segue a convergência de seus interesses e a possibilidade da aliança entre ambas contra a nobreza. E nesse sentido, a burguesia, a princípio, tende a apoiar a insurreição camponesa como ocorreu nas revoluções francesas, em que tal aliança se forja e se mostra decisiva para a consolidação da burguesia no poder. No entanto, no caso alemão, a burguesia opta por trair o campesinato e se aliar a nobreza, estabelecendo uma relação anômala com esta classe.

É a prova mais concludente de que a revolução alemã de 1848 é apenas a paródia da Revolução Francesa de 1789. Em 4 de agosto de 1789, três semanas após a tomada da Bastilha, em um dia o povo francês deu cabo dos encargos feudais. Em 11 de julho de 1848, quatro meses após as barricadas de março, os encargos feudais deram cabo do povo alemão (...). A burguesia francesa de 1789 não abandonou um só instante seus aliados, os camponeses. Ela sabia que a base de sua dominação era a destruição do feudalismo no campo, a criação de uma classe de camponeses livres e proprietários. A burguesia alemã de 1848 traiu sem qualquer decoro os camponeses, seus aliados mais naturais, a carne de sua carne, e sem os quais ela é impotente ante a nobreza (p. 181).

O potencial revolucionário burguês é substituído pela atuação no terreno do direito, que consolida sua ação nos anos de 1848-1849. O "Projeto de Lei para a Organização da Guarda Civil" é mais uma prova, dentre várias, do caráter contrarrevolucionário da burguesia prussiana, que ao invés de garantir uma maior autonomia da guarda civil pela defesa de seus interesses revolucionários propõe impedir seus integrantes de possuírem uma vida civil ativa, além de cindir, em seu interior, os proprietários dos não proprietários. 
A guarda civil cumpre o papel de proteção da população e, em tempos revolucionários, toma parte nos embates atuando, muitas vezes, decisivamente. É composta pela população em geral e, justamente por esta razão, seu potencial de intervenção é considerável, pois reflete, em seu interior, os mais diversos posicionamentos vigentes na sociedade. Assim, instituiu-se aos indivíduos integrantes da guarda se abster das questões políticas, e de seus direitos como cidadãos, permanecendo apenas como instrumentos da coroa. Portanto,

O bravo homem recebeu as armas e a farda sob a condição de previamente renunciar aos seus principais direitos políticos, o direito de associação, etc. Sua missão, proteger a "liberdade constitucional", resolve-se segundo a "natureza de sua função", em executar cegamente as ordens das autoridades superiores, em troca a liberdade civil usual, admitida mesmo sob a monarquia absoluta, pela obediência passiva, abúlica e desinteressada do soldado (p. 156).

E a liberdade constitucional defendida por aqueles que estavam no governo é a liberdade de deliberação favorável ao próprio governo, ou seja, à nobreza e à burguesia; é a liberdade de impedir que as reivindicações da classe trabalhadora alcancem o escopo do Estado. E sob esta afirmação retórica de "liberdade constitucional", as ações contrarrevolucionárias se consolidam e o povo perde, a cada dia, o seu março. Para cada exigência popular o governo elabora uma medida na mesma intensidade, porém em sentido contrário.

Vocês exigiram milícia popular? Devem receber em regulamento de serviço. Devem ser postos à disposição das autoridades, prestar o serviço militar e educar-se na obediência passiva até seus olhos se encherem de lágrimas.(...)Ainda mais reivindicações constitucionais! Ainda mais reivindicações constitucionais! 
Clama o Ministério de Ação. Para cada reivindicação temos uma ação. Reivindicação: todo cidadão deve ser armado para proteger a "liberdade constitucional". Resposta: Todo cidadão está, de agora e, diante, sob a competência do ministério do Interior (p. 157).

Na lei de reorganização da guarda civil é instituída uma diferenciação entre os membros da guarda que são burgueses e aqueles que são proletários, qual seja, aquele que possui recursos para adquirir seu uniforme e sua arma possui o direito de permanecer armado, pois não é compelido a entregar seu equipamento para retenção de seus superiores. Já aquele que não possuí condições de adquirir seu equipamento, recebe-o do governo, mas fica vetado seu acesso a ele, salvo sob autorização em momento de serviço. Ou seja, para que este disponha de acesso ao armamento e ao uniforme, o governo precisa autorizar tal acesso. Ora, isso implica que aqueles que possuem recursos para se armar, i.e., a burguesia, estarão sempre armados e prontos a defender seus interesses. Por sua vez, os trabalhadores, que não possuem as condições financeiras para se equipar, estarão a mercê do governo e, consequentemente, não terão acesso ao armamento assim que se levantarem impulsionados por seus próprios interesses. Vemos claramente aqui a intenção de desarmar o povo e minimizar sua ameaça frente ao estado. A guarda se torna, assim, um apêndice do poder jurídico, um subordinado do governo ao invés de se tornar uma milícia popular, que defenda e expresse a revolução.

Com o povo oficialmente desarmado, legalmente sem acesso aos meios de se salvaguardar, é possível avançar cada vez mais com o processo contrarrevolucionário. Mas para consolidar o governo reacionário é necessário resolver as questões econômicas. O estado prussiano, em dificuldades financeiras, precisa encontrar meios de se reerguer, e nada mais adequado que repassar ao povo o ônus da dívida. É assim que surge o "Projeto de Lei sobre o Empréstimo Compulsório". Com uma manobra jurídica, procura impelir a população a conceder um 
empréstimo ao governo; não obtendo sucesso nesse empreendimento, propôs a lei que impõe as pessoas a concessão do empréstimo ao estado.

Oestado, em grandes apuros, apelou para o patriotismo. Solicitou gentilmente ao patriotismo que depositasse no altar da pátria 15 milhões de táleres, e além do mais não como um presente, mas somente como empréstimo voluntário. Temos a mais alta confiança no estado, mas mantemo-nos surdos ao seu grito de socorro! Encontramo-nos infelizmente em tal "incerteza" quanto à "real necessidade do estado" que, com grande sofrimento espiritual, decidimos não the dar absolutamente nada. Temos mesmo a mais alta confiança na autoridade estatal, e a honrada autoridade estatal alega que o estado necessita de 15 milhões. Mesmo com confiança, não acreditamos na garantia da autoridade estatal, e na verdade consideramos sua gritaria por 15 milhões como uma mera brincadeira (p. 169).

Ora, o apelo ao sentimento nacionalista não produz o efeito desejado, posto que tal sentimento não possui nenhuma relação com a vida imediata dos trabalhadores e, ao se tratar de uma lei que interfere diretamente nas possibilidades de sobrevivência do povo, $\mathrm{o}$ sentimento nacional se mostra vazio de conteúdo. "A crise ministerial e comercial saqueia os juros ao capital da sociedade civil. O estado ajuda a sociedade civil a se reerguer tirando-lhe também o capital" (p.168). Insatisfeito com a recusa do povoem emprestar voluntariamente seu dinheiro, o ministério instaura o empréstimo compulsório; se não emprestam "voluntariamente", devem emprestar da mesma forma. E o único vencedor é o burguês, uma vez que lucra com tal transação, pois o governo estabelece juros mais altos para aqueles que emprestam voluntariamente; o único que se enquadra nesse perfil é o detentor de 
capital, enquanto aquele cujo empréstimo é compulsório não obtêm nenhuma vantagem, ou seja, o povo.

E para assegurar a traição à revolução e a implementação deste conjunto de leis, é necessário censurar a imprensa. No século XIX a imprensa cumpre um papel fundamental no interior dos debates políticos, dado que os periódicos encontram-se atrelados a uma concepção específica e advogam a favor desta. Estes debates no interior das publicações são intensos e possibilitam a constituição de um ambiente crítico. A NGR não é diferente neste aspecto, inclusive defende em suas páginas que "(...) a imprensa tem não só o direito, tem o dever de fiscalizar rigorosamente os senhores representantes do povo"(p.137), ou seja, a imprensa não pode seeximir dos acontecimentos políticos, dado que seu papel é refletir os fatos, é criticá-los e a partir disto apresentar uma posição bem definida. Porém, tal ambiente se torna um empecilho para as ações dos governantes, considerando que este poderia ser um meio de insuflar o povo contra o estado através de denúncias e críticas. Assim, é significativo censurar a imprensa em geral, salvo os casos em que a folha se encontra ajustada aos ideais do estado. O "Projeto de Lei de Imprensa Prussiano" é fruto deste embate entre o governo e o povo, e a possibilidade deste se expressar. A tentativa é inibir as críticas e denúncias realizadas no interior dos jornais através de penalidades duras e contra aqueles que permanecem com a postura de ataque ao governo.

Portanto, na nova jurisdição, a denúncia se torna assunto de polícia e qualquer acusação é passível de condenação, dado que o governo não produz provas contra si mesmo e seus pares, afinal, um "documento legal" só pode vir das mãos dos próprios acusados. Logo, as denúncias podem ser tratadas como calúnias e passíveis de condenação. Ou seja, quando se trai o povo e refugia-se na constituição os embates tornam-se assunto de caserna.

A apresentação destas leis, a reflexão sobre seu real impacto e a dissolução de seu invólucro mistificador, permite compreender a real atuação do estado e como este se estrutura para beneficiar uma 
dada classe. Como foi afirmado anteriormente, a figura do estado, em si mesma, nada representa a não ser uma mera mistificação. "A existência do poder soberano é justamente seus funcionários, exército, administração, juízes. Abstraindo deste seu corpo ele é uma sombra, uma ilusão, um nome" (p. 482). Assim, afirmar algo sobre o caráter do estado é dizer quem o está controlando e a quem ele está a serviço.

As leis que foram analisadas até aqui são uma amostra desta relação postas no escopo do estado. Cada uma delas, claramente, serve a um dado interesse específico, que privilegia uns em detrimento de outros. Isso porque a atuação do estado necessariamente está atrelada à elaboração e aplicação de um conjunto de leis, uma vez que apenas se efetiva na forma jurídica, um de seus aspectos constitutivos. Assim, para atingir as relações sociais, para garantir a efetivação de seus interesses, ou seja, dos interesses daqueles que o detém, é necessário transformálos em leis, em uma jurisdição que permite a realização das mesmas. Por exemplo, se é necessário retirar o povo das decisões políticas, criase um certo tipo de lei; se é necessário, como vimos, desarmar o povo, cria-se uma lei e o estado é capaz de fazer valer suas decisões. Portanto, a classe que o dirige consolida seus interesses particulares através de medidas estatais que nascem na órbita do estado.

No interior dos processos revolucionários que aconteceram na história até então, as assembleias constituintes integraram o espaço de legitimação da vontade popular no curso da reconstituição do poder, tendo em vista atender as necessidades da nova sociabilidade assim constituída. E mesmo no caso da Prússia, na qual a assembleia se forma sem seus poderes soberanos, a conciliação não é pacífica e a assembleia é forçada a assumir seu real papel.

Ao decidir assumir seu caráter constituinte e deliberar a favor das reivindicações da revolução, a assembleia choca-se com a coroa. A solução para o impasse é, do ponto de vista da coroa, a dissolução da assembleia e, do ponto de vista desta, a organização do povo, a pressão revolucionária e a transformação das velhas instituições administrativas e políticas, ou seja, a dissolução da coroa. "Se a Assembleia está em 
posição de igualdade em face da Coroa, a Coroa não tem nenhum direito de dissolver a Assembleia. Caso contrário, consequentemente, a Assembleia possuiria do mesmo modo o direito de depor o rei" (p. 211).

No entanto, a traição da revolução por parte da burguesia e a debilidade da assembleia fazem com que a coroa consiga dissolvê-la no final do ano de 1848. "A contrarrevolução chegou a seu segundo estágio. A Assembleia Nacional foi dissolvida. Uma constituição outorgada foi anunciada sem mais pela 'Altíssima Majestade'" (p. 315). A coroa consegue dar o golpe derradeiro no processo iniciado em março de 1848, fazendo seus privilégios prevalecerem frente às reivindicações populares. "A camarilha, os junkers, a burocracia e toda a reação com ou sem uniforme se rejubila por finalmente poder outra vez tanger o povo rude de volta para o estábulo do estado 'germanocristão'"(p. 315).

E tal vitória se deu através dos mecanismos político-jurídicos que acabaram com as ameaças que ainda representavam a assembleia e o povo. A revolução é derrotada não no campo revolucionário, mas no campo do direito.

Aos olhos da coroa, a Revolução de Março foi um fato brutal. Um fato brutal só pode ser extirpado por outro. Cassando as novas eleições sobre a base da lei de abril de 1848, o ministério nega sua responsabilidade, cassa o próprio foro perante o qual era responsável. O apelo da Assembleia Nacional ao povo transformou-se, assim, dai em diante, em pura aparência, em ficção, em logro. Inventando uma primeira câmara censitária como parte integrante da Assembleia legislativa, o ministério rasgou as leis orgânicas, perdeu o terreno do direito, falsificou as eleições populares, privou o povo da qualquer julgamento sobre o "ato salvador" da coroa (p. 460). 
Enquanto poder constituído, a coroa poderia ter agido no campo contrarrevolucionário, assumido o golpe de estado e, com a dissolução da assembleia, demarcaria sua posição perante o outro poder instituído em disputa aberta com ele. No entanto, prefere os meandros do terreno do direito, deslegitimando as leis orgânicas, descreditando as eleições oficiais e escamoteando-se das pressões, tanto do povo quanto da burguesia. Consolida sua contrarrevolução sem assumir explicitamente o papel da reação.

Portanto, (...) os fatos não se deixam negar, nenhum historiador futuro os negará: a coroa fez uma revolução, calcou aos pés a situação legal, não pode apelar as leis que ela mesma tão vergonhosamente derrubou.(...) Depois de consumada uma revolução ou contrarrevolução, as leis derrubadas não podem ser usadas contra os defensores dessa mesmas leis. Isto é uma covarde hipocrisia da legalidade (p. 460).

E, no entanto, o governo, mesmo executando uma contrarrevolução, persegue seus opositores no campo do direito, demonstrando, primeiro, como os governantes prussianos se refugiam no terreno legal, e, depois, como eles pretendem camuflar da população a revolução que empreenderam.

O campo do direito é propício para ação da burguesia no presente contexto, uma vez que este constitui uma universalidade formal que abstraí as diferenças e contradições presentes no interior da sociedade em questão. Isto permite a ela assumir e se utilizar de leis que foram derrubadas pelo processo revolucionário, assim como sancionar outras tantas que, sob a carapuça jurídica, visam sempre favorecer seus interesses particulares. Vale dizer que, seguindo os dizeres de Marx, não existe um direito em si mesmo, i.e., uma formulação jurídica cujo conteúdo é independente dos caminhos e descaminhos dos acontecimentos históricos. Todavia, o formalismo intrínseco ao campo 
jurídico permite à burguesia manobrar de maneira "hipócrita" por este terreno, tendo em vista mascarar suas reais intenções.

A coroa, ao constituir um contexto jurídico em que pôde dissolver a Assembleia, na verdade, perpetra um golpe de Estado, uma revolução no sentido da reação. O que fica claro é que o terreno do direito não está desconectado das relações sociais e não é um campo isento das influências de tais relações. Ao contrário, ele é um instrumento de intervenção direta nos processos reais. Não é nada além de uma expressão das relações efetivamente existentes e como tal não é capaz de modificar substancialmente tais relações, mas apenas impedir que elas se modifiquem. E é por isso que o embate desenvolvido no interior da Prússia não se soluciona pela via legal, mas sim, apenas, através da luta direta entre os agentes envolvidos.

É no terreno do direito que encontramos o embate entre a antiga estrutura de poder e a tentativa de estruturação de uma nova forma de governo, no caso prussiano. Ele é transportado do campo revolucionário para o direito, uma vez que, como já dissemos, o âmbito revolucionário é o lugar da transformação e, ao não assumir uma postura de luta em busca desta transformação, a burguesia se esquiva do enfrentamento com a aristocracia, se recolhendo ao campo do direito e se conciliando com a coroa. A utilização da Dieta Unificada como aval da nova legislação é a prova mais contundente de que o novo governo, burguês, procura estabelecer uma linha de continuidade com a antiga forma de governo, anterior ao processo revolucionário.

A união entre as classes burguesa e feudal explicita os pontos de identidade com relação a seus interesses. Mas isso não significa que a totalidade de tais interesses coincidem, muito pelo contrário, burguesia e nobreza se contrapõem na busca de seus próprios benefícios, demonstrando que a conciliação entre ambas possuía limites intransponíveis. Muito além disso, elas são representantes de sociabilidades distintas que, no curso da história, se contrapõem. A conciliação é a tentativa de harmonizar uma nova sociedade com 
arcaicas estruturas de poder. Pois bem, tal arranjo não pode perdurar continuamente e a nova sociedade tende a prevalecer, posto que as relações efetivas já se transformaram e, consequentemente, exigem novas estruturas. Essa composiçãosóé possível devidoà implementação de leis que ora beneficiam uma, ora beneficiam outra classe.

Ou seja, o "terreno do direito" representa o freio do desenvolvimento da nova sociabilidade ao conciliar o novo com o velho, paralisa o desenvolvimento das novas relações sociais que já existem no interior da Alemanha, enquanto o processo revolucionário é o salto que possibilitava a consolidação do novo por varrer o arcaico. E a responsável por isso é a burguesia com sua covardia e inaptidão política, que defende, acima de tudo, o terreno do direito e não a revolução de março.

\section{Bibliografia}

MARX, Karl. A Nova Gazeta Renana. Trad. Lívia Cotrim. São Paulo: Educ, 2010.

. \& ENGELS, Friedrich. La Nouvelle Gazette Rhénane. Tomos I a III. Paris: Éditions Sociales, 1963-71

. \& ENGELS, Friedrich. Correspondance, tomos I e II. Paris: Éditions Sociales, 1977.

. As lutas de classes na França (1848-1850). Trad. Antônio Roberto Bertelli. São Paulo: Global, 1986.

CLAUDIN, Fernando. Marx, Engels y la revolución de 1848. Madrid: Siglo Veintiuno, 1975. 
DROZ, Jacques. Europa: Restauracion y revolucion: 1815-1848. Trad. Ignacio Romero de Solis. Mexico: Siglo Veintiuno, 1974.

CHASIN, José. Marx no tempo da nova gazeta renana. In: A burguesia e a contra-revolução. São Paulo: Cadernos Ensaio Pequeno Formato I, Ensaio, 1991.

138 "Quem tem o poder, tem o direito". Marx e a relação entre o Direito... 